\title{
Assessment of the Dynamic Response of Buildings: Experimental Monitoring and FEM Simulations
}

\author{
[L. de S. Bastos, A. Barile, J. G. Santos da Silva, G. L. Debona]
}

\begin{abstract}
Numerical analysis using FEM (Finite Element Method) simulations is part of the everyday routine in many academic centres and structural design. However, one of the main problems to do this task is related to the numerical modelling reliability, aiming to represent the investigated structure real behaviour. This way, in this investigation experimental methodologies allow characterizing the proposed physical structural model of a 19 story building, constructed in laboratory, based on the use of HDF (High Density Fibreboard). In sequence, aiming to validate the motion equations of the structural system, both numerical and experimental dynamic responses of the physical model were correlated. The results are presented in terms of modal parameters, frequency response functions (FRFs) and time history. The good agreement between the numerical and experimental results can corroborate the adequate use of the developed numerical model.
\end{abstract}

Keywords-Buildins, Dynamic Analysis, Experimental Dynamic Monitoring, Finite Element Method.

\section{Introduction}

Numerical analysis using FEM (Finite Element Method) simulations is part of everyday routine of many academic centres and structural design offices around the world. However, one of the problems to do this task is the FEM model reliability, in order to represent the actual response of the analysed structure [1-3].

Currently, it is possible to use the results of dynamic experimental monitoring to verify and adjust the numerical model and consequently improve accuracy of the results [4]. The experimental dynamic monitoring makes possible the extraction of modal parameters, such as: natural frequencies, vibration modes and damping coefficients. These parameters are relevant for a correct characterization of the studied model and calculated based on the acceleration and velocity experimental signals obtained on the investigated structure, measured using accelerometers or laser vibrometry [1-3].

This way, in this research work, the modal parameters of a real 19 story building, constructed in laboratory [1-3], based on the use of HDF (High Density Fibreboard) are obtained, based on experimental dynamic monitoring, and used to calibrate the developed FEM. After that, a forced vibration analysis is carried out and the dynamic response of the building, when subjected to impact loads, was compared with the actual structural response of the HDF building model. The conclusions emphasize the relevance of using the dynamic experimental monitoring aiming to characterize and adjust the developed FEM of the investigated building.

L.S. Bastos, A. Barile, J.G. Santos da Silva

State University of Rio de Janeiro (UERJ)

Rio de Janeiro/RJ, Brazil

G.L. Debona

Rural Federal University of Rio de Janeiro (UFRRJ)

Rio de Janeiro/RJ, Brazil

\section{Investigated Building}

The investigated structural model is related to a real 19 story building, constructed in laboratory, based on the use of HDF (High Density Fibreboard), see Figure 1. This model simulates a building presenting indoor height between floors of $8.8 \mathrm{~cm}$, floor dimensions of $20 \mathrm{~cm} \mathrm{x} 40 \mathrm{~cm}$ and total height of $167.2 \mathrm{~cm}$, see Figure 2. The columns present dimensions of $0.3 \mathrm{~cm} \times 2.0 \mathrm{~cm}$ and the slabs present a $0.3 \mathrm{~cm}$ thickness. The used HDF presents a density equal to $841 \mathrm{~kg} / \mathrm{m}^{3}$ and a Young modulus of 3272MPa.

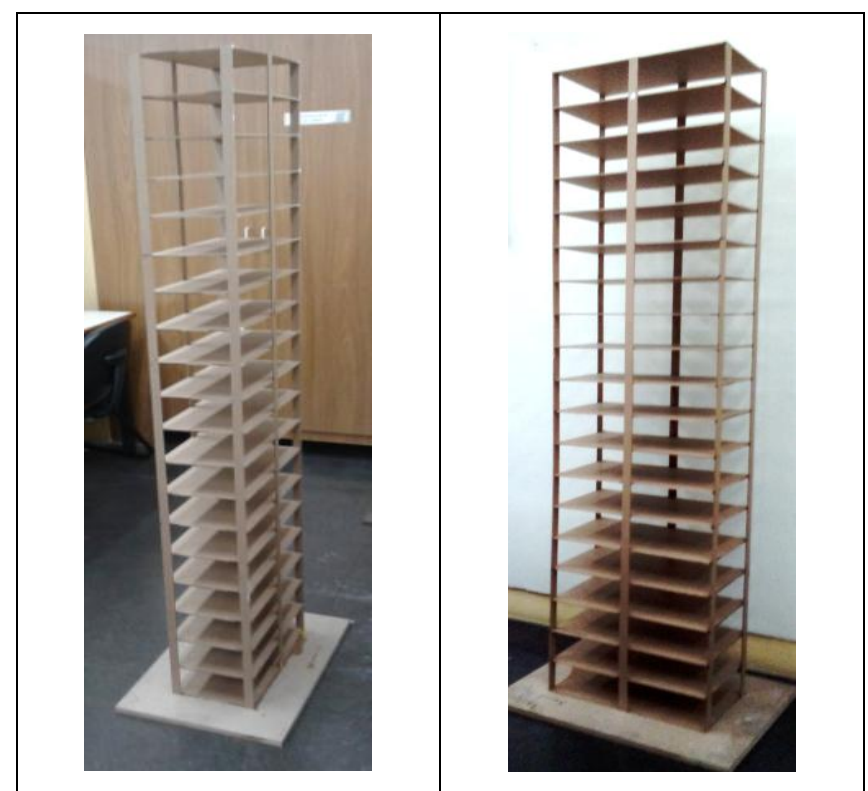

Figure 1. Investigated 19 story HDF building constructed in laboratory.

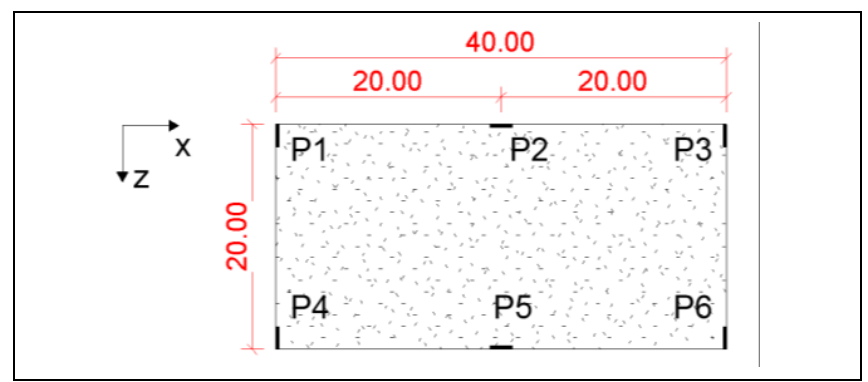

Figure 2. Floor dimensions of the investigated structural model.

\section{FEM of the Building}

The proposed computational model, developed for the reinforced concrete building dynamic structural analysis, adopted the usual mesh refinement techniques present in finite element method simulations implemented in the ANSYS computational program [5]. In this numerical model, the concrete floor girders were represented by threedimensional beam elements (BEAM44 [5]), where flexural and torsion effects are considered. The concrete slab was 
Proc. of Eighth International Conference On Advances in Civil, Structural and Mechanical Engineering - ACSM 2018 Copyright (C) Institute of Research Engineers and Doctors, USA. All rights reserved.

ISBN: 978-1-63248-154-2 doi: 10.15224/978-1-63248-154-2-13

represented by shell elements (SHELL63 [5]), see Figures 3 and 4 . It must be emphasized that the connection between columns and slabs have used multi-point constraint element (MPC184 [5]) that connects a column with three nodes of the slab. This strategy was necessary, aiming to improve the numerical modelling, when comparing with the actual structural behavior of building. Regarding the boundary conditions, the rigid support hypothesis is used, where the columns were restricted at the model bottom. The developed building FEM presents an appropriate degree of refinement, allowing a good representation of the dynamic behavior of the investigated HDF building model, see Figures 3 and 4.

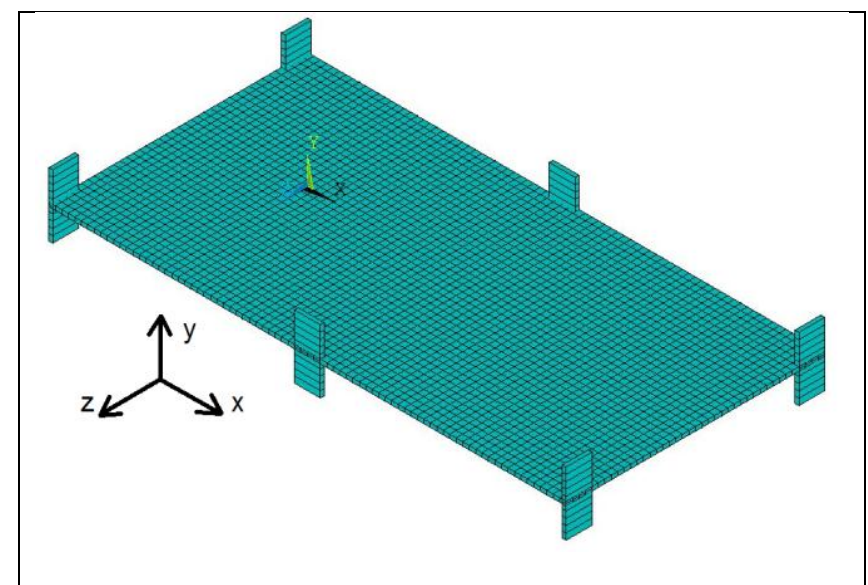

Figure 3. FEM: typical floor of the investigated model.

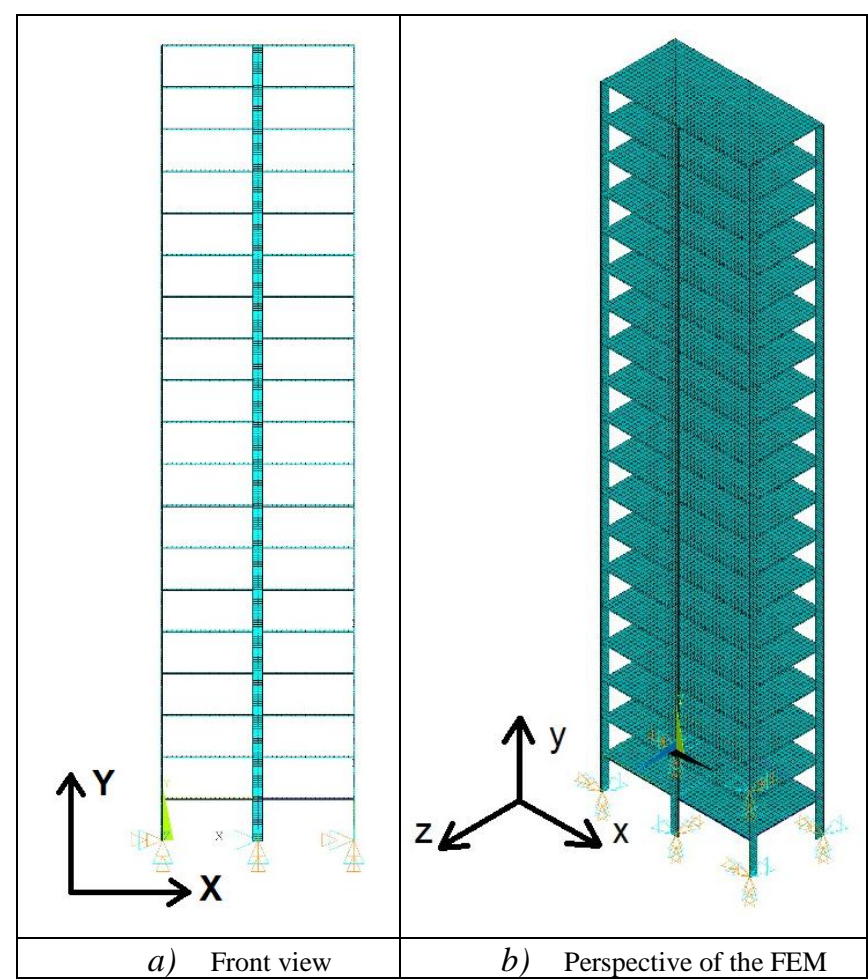

Figure 4. FEM: three-dimensional finite element model of the building.

\section{Iv. Modal Analysis}

The natural frequencies (eigenvalues) and the vibration modes (eigenvectors) of the investigated structural model were obtained with the aid numerical methods of extraction (modal analysis), based on a free vibration analysis, performed with the use the program ANSYS [5].
It must be emphasized that the investigated structural model can vibrate in many different ways and these different mode shapes of vibrating present their own natural frequency. In Figure 5, the first six vibration modes of the analysed structural model and their respective natural frequencies are presented.

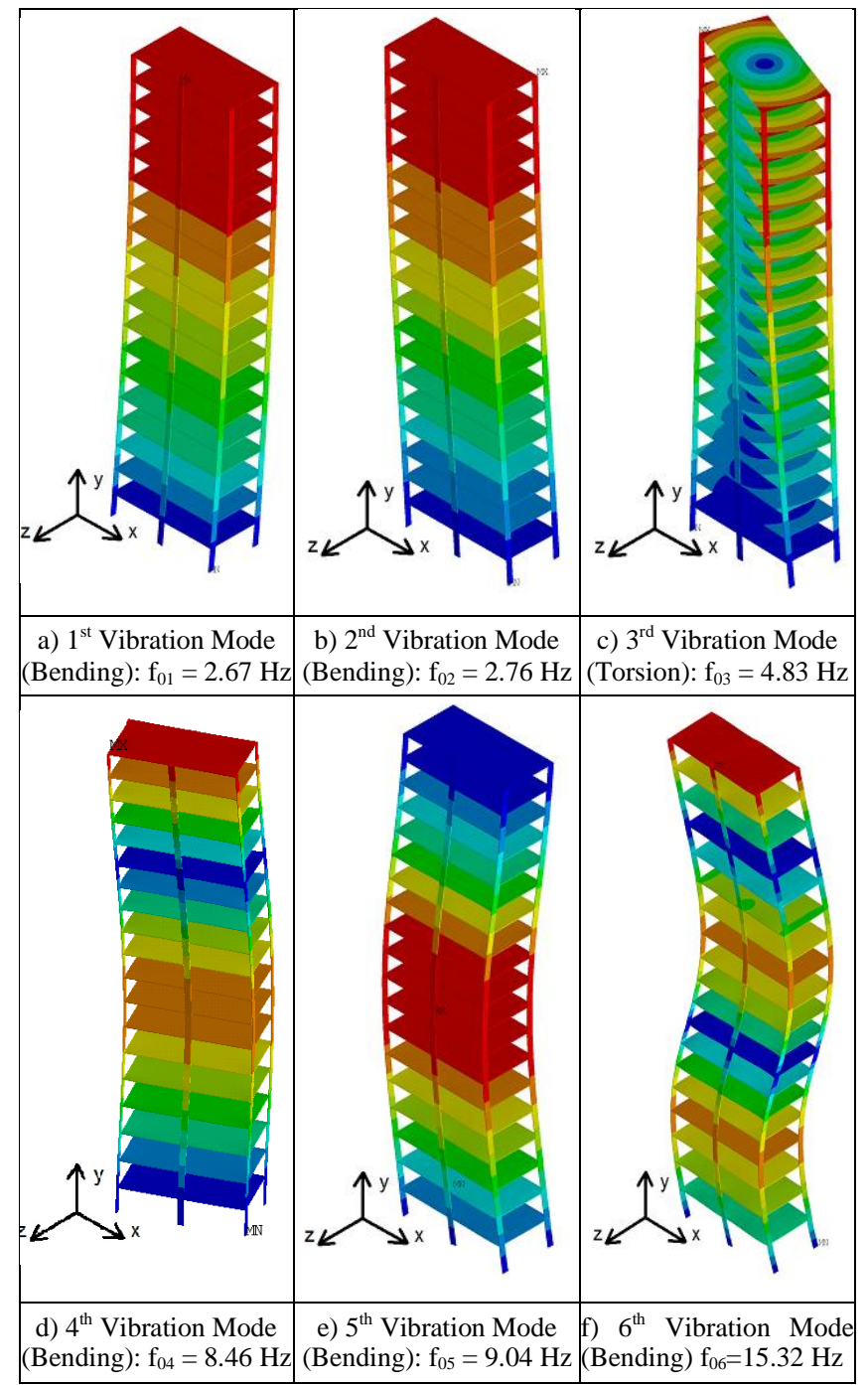

Figure 5. Natural frequencies and vibration modes of the building.

\section{v. Dynamic Experimental Monitoring}

The dynamic experimental monitoring was performed based on the use of three unidirectional accelerometers, aiming to obtain the natural frequencies and vibration modes of the model. The accelerometers were positioned at the heights of $167.1 \mathrm{~cm} ; 144.1 \mathrm{~cm}$ and $61.6 \mathrm{~cm}$ of the structure, modifying the position of the accelerometers in each experimental test, in order to obtain the mode shapes of the building at the $\mathrm{X}$ and $\mathrm{Z}$ directions. In sequence, Tables I and II present the general characteristics of the accelerometers.

\section{TABLE I. CAPACITIVE ACCELEROMETER}

\begin{tabular}{|c|c|c|}
\hline $\begin{array}{c}\text { Model of the } \\
\text { Accelerometers }\end{array}$ & $\begin{array}{c}\text { Frequency Range } \\
(\mathbf{H z})\end{array}$ & $\begin{array}{c}\text { Measurement Range } \\
(\mathbf{m V} / \mathbf{g})\end{array}$ \\
\hline DYTRAN 7521A1 & $0-1500$ & 549.27 \\
\hline
\end{tabular}


Proc. of Eighth International Conference On Advances in Civil, Structural and Mechanical Engineering - ACSM 2018 Copyright (C) Institute of Research Engineers and Doctors, USA. All rights reserved.

ISBN: 978-1-63248-154-2 doi: 10.15224/978-1-63248-154-2-13

TABLE II. RESISTIVE ACCELEROMETER

\begin{tabular}{|c|c|c|}
\hline $\begin{array}{c}\text { Model of the } \\
\text { Accelerometers }\end{array}$ & $\begin{array}{c}\text { Frequency Range } \\
(\mathbf{H z})\end{array}$ & Shunt Eng \\
\hline $\begin{array}{c}\text { KYOWA FU } \\
590022\end{array}$ & $0-41$ & 6.501486 \\
\hline $\begin{array}{c}\text { KYOWA FU } \\
590024\end{array}$ & $0-45$ & 7.233545 \\
\hline
\end{tabular}

Initially, two free vibration experimental tests were performed with relation the $\mathrm{X}$ and $\mathrm{Z}$ directions. The test consists of causing a small displacement on the model and then let it vibrate freely. Each signal from the accelerometers was recorded along the time for analysis.

The forced vibration tests were performed using an impact hammer with a coupled accelerometer, and its dynamic force was applied at a height of $149.6 \mathrm{~cm}$ at the $X$ and $\mathrm{Z}$ directions. The velocity was captured by laser vibrometry (PDV System), at a height of $158.4 \mathrm{~cm}$. The characteristics of the equipment are presented in Table III.

TABLE III. PDV SYSTEM

\begin{tabular}{|c|c|c|}
\hline $\begin{array}{c}\text { Model of the } \\
\text { Equipment }\end{array}$ & $\begin{array}{c}\text { Frequency Range } \\
(\mathbf{H z})\end{array}$ & $\begin{array}{c}\text { Measurement Range } \\
(\mathbf{m m} / \mathbf{s} / \mathbf{V})\end{array}$ \\
\hline PDV 100 & $0.5 \mathrm{~Hz}-22 \mathrm{kHz}$ & 125 \\
\hline
\end{tabular}

TABLE IV. IMPACT HAMMER

\begin{tabular}{|c|c|c|}
\hline $\begin{array}{c}\text { Model of the } \\
\text { Equipment }\end{array}$ & $\begin{array}{c}\text { Frequency Range } \\
(\mathbf{H z})\end{array}$ & $\begin{array}{c}\text { Measurement Range } \\
(\mathbf{m V} / \mathbf{g})\end{array}$ \\
\hline $\begin{array}{c}\text { Hammer DYTRAN } \\
\text { DYNAPULSE }\end{array}$ & - & - \\
\hline $\begin{array}{c}\text { Accelerometer } 353 \\
\text { MP197 }\end{array}$ & $1-700$ & 10.18 \\
\hline
\end{tabular}

\section{A. Free vibration: PDV system}

In order to verify the reliability of the experimental results obtained based on the use of accelerometers, the same free vibration tests were also carried out using the PDV system. This way, Figure 6 presents the velocity signal, along the time, at a height of $158.4 \mathrm{~cm}$, considering the model in free vibration parallel to the $\mathrm{X}$ direction. The frequency spectrum is presented in Figure 7 , and it is possible to identify the natural frequencies related to the $1^{\text {st }}$ vibration mode $\left(\mathrm{f}_{01}=2.45 \mathrm{~Hz}\right)$ and $5^{\text {th }}$ vibration mode $\left(\mathrm{f}_{05}=\right.$ $7.84 \mathrm{~Hz}$ ), both mode shapes related to the bending around the $\mathrm{Z}$ axis.

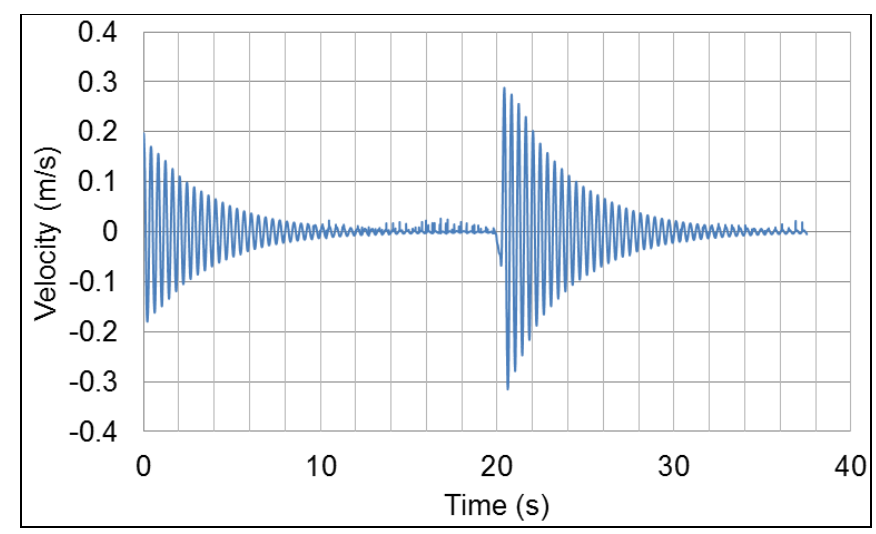

Figure 6. Experimental measured velocity: $\mathrm{X}$ direction $(\mathrm{h}=158.4 \mathrm{~cm})$.

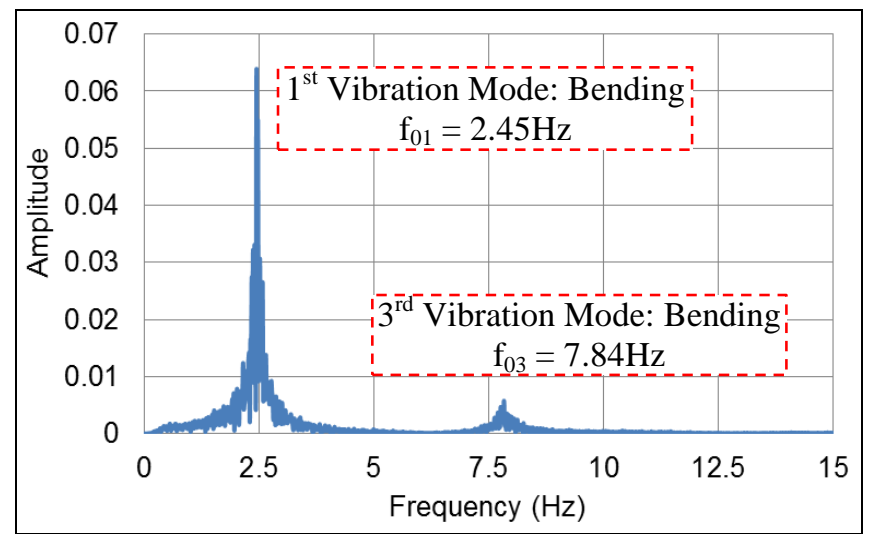

Figure 7. Velocity frequency spectrum: $\mathrm{X}$ direction $(\mathrm{h}=158.4 \mathrm{~cm})$.

The result regarding free vibration parallel to the $\mathrm{Z}$ axis is presented in Figure 8. Figure 9 presents the frequency spectrum of this signal obtained through the Fourier transform. It is possible to obtain the natural frequencies referring to the $2^{\text {nd }}$ Vibration Mode $(2.71 \mathrm{~Hz})$ and $4^{\text {th }}$ Vibration Mode $(9.07 \mathrm{~Hz})$.

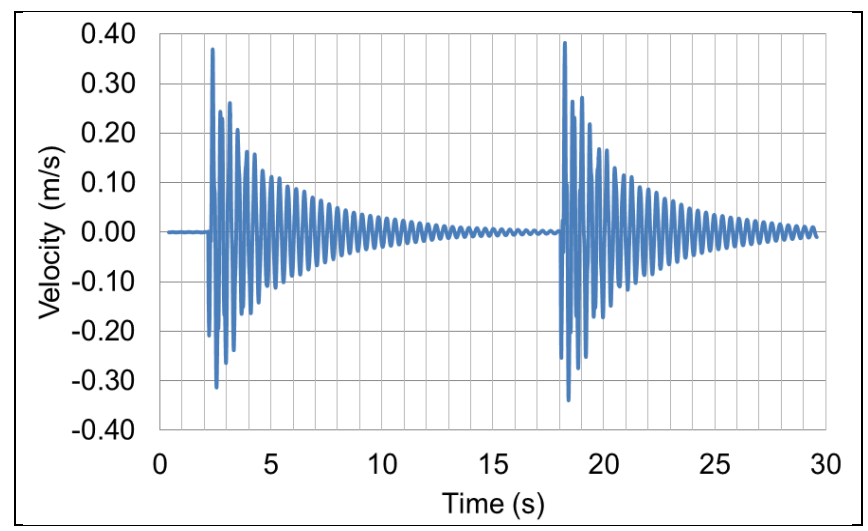

Figure 8. Experimental measured velocity: $\mathrm{Z}$ direction $(\mathrm{h}=158.4 \mathrm{~cm})$.

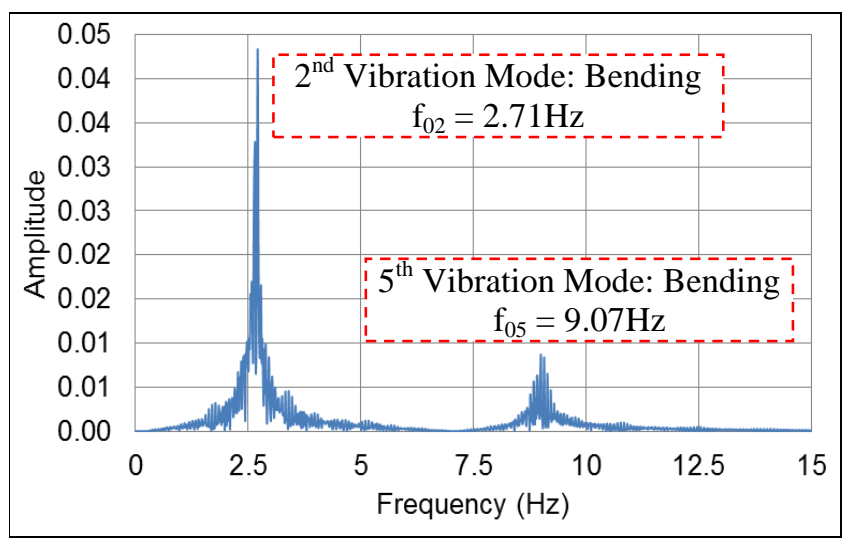

Figure 9. Velocity frequency spectrum: $\mathrm{Z}$ direction $(\mathrm{h}=158.4 \mathrm{~cm})$.

Despite the excellent accuracy offered by the PDV system (laser vibrometry), this type of experimental dynamic monitoring presents the disadvantage of measuring the signal only at one single point on the structural model each time.

On the other hand, it is not so easy to identify the mode shapes of the investigated building using this technique (PDV system). This way, the vibration modes of the building were properly identified based on the use of the accelerometers. 
Proc. of Eighth International Conference On Advances in Civil, Structural and Mechanical Engineering - ACSM 2018 Copyright (C) Institute of Research Engineers and Doctors, USA. All rights reserved.

ISBN: 978-1-63248-154-2 doi: 10.15224/978-1-63248-154-2-13

\section{B. Forced vibration: PDV system}

In sequence of the investigation, the structural model was subjected to forced vibration tests, based on the use of impulsive loads. The impulsive load was applied at a selected point on the structural model $(\mathrm{h}=149.6 \mathrm{~cm})$, at the global X direction, based on the use of an impact hammer connected to an accelerometer. In sequence, Figure 10 presents the impulsive load applied on the model using the impact hammer. The investigated model dynamic response, in time and frequency domains is presented in Figures 11 and 12 , respectively. The same experimental test was also carried out considering the global $\mathrm{Z}$ direction and the building dynamic response in time and frequency can be observed in Figures 13 and 14, respectively.

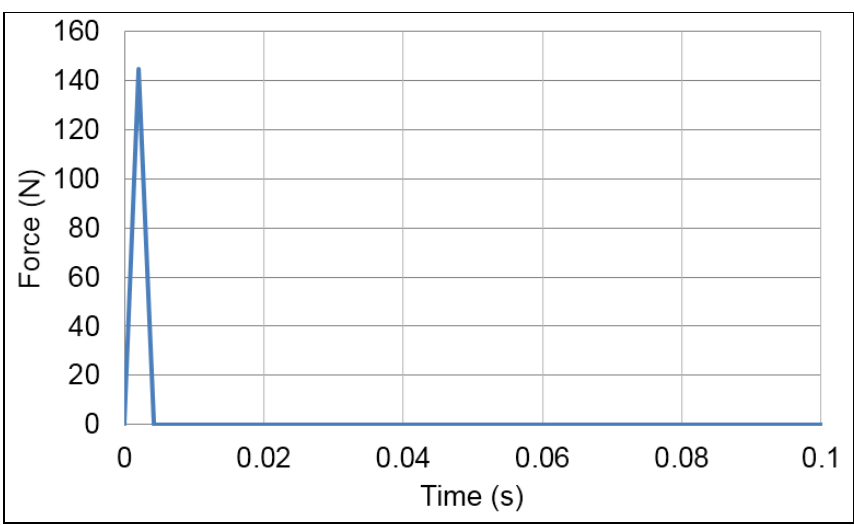

Figure 10. Experimental impact hammer force: $X$ direction $(h=149.6 \mathrm{~cm})$.

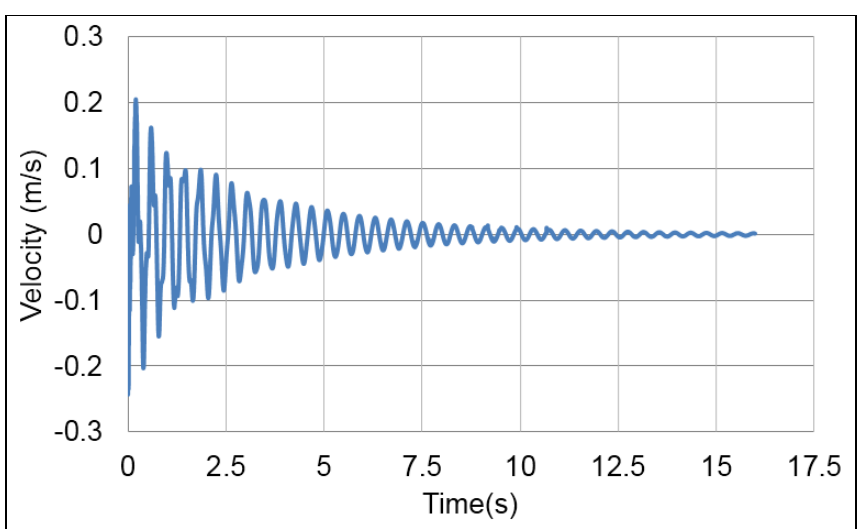

Figure 11. Experimental measured velocity: $\mathrm{X}$ direction $(\mathrm{h}=158.4 \mathrm{~cm})$.

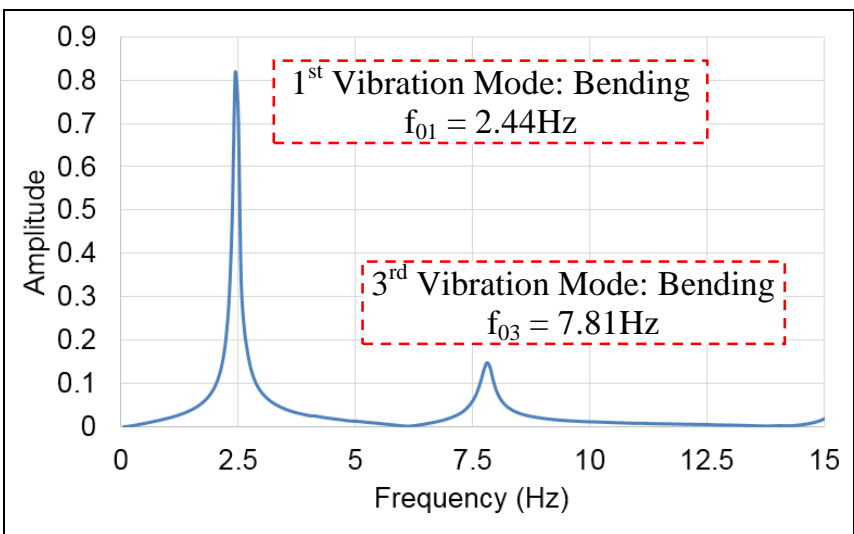

Figure 12. Velocity frequency spectrum $(F R F)$ : $X$ direction $(h=1.584 \mathrm{~cm})$.

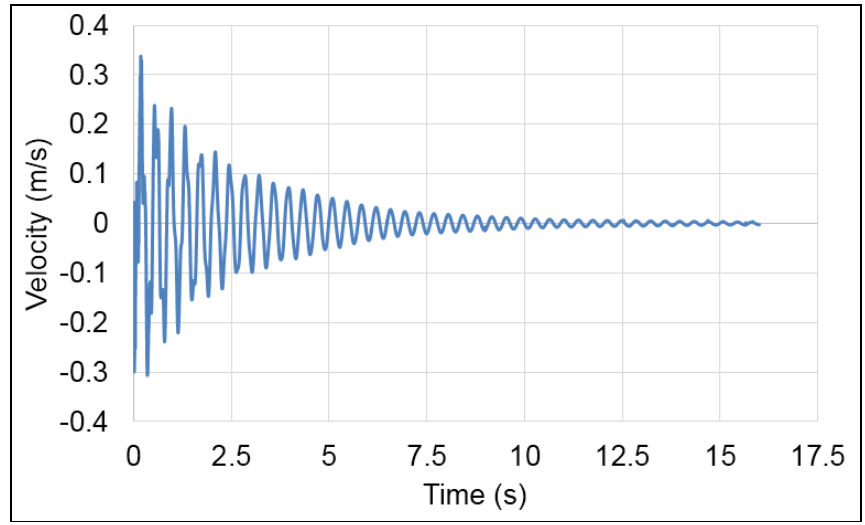

Figure 13. Experimental measured velocity: $\mathrm{Z}$ direction $(\mathrm{h}=158.4 \mathrm{~cm})$.

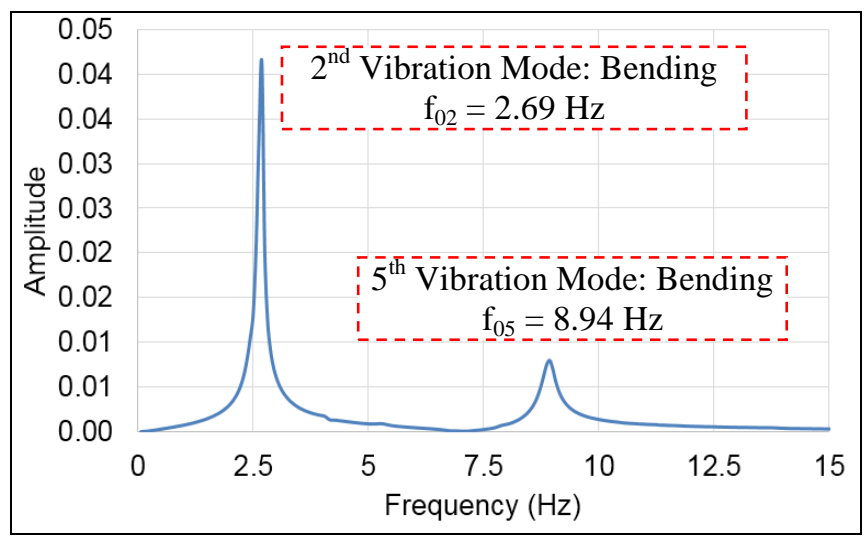

Figure 14. Velocity frequency spectrum $(\mathrm{FRF})$ : $\mathrm{Z}$ direction $(\mathrm{h}=1.584 \mathrm{~cm})$..

\section{Damping coefficients}

The dynamic structural response of the investigated building is influenced by the damping coefficients. These damping coefficients determine the amplitude of vibration at the resonance and also the time of persistence of this vibration after there are no dynamic excitations. Thus, in this research work, the damping coefficients were determined for the following vibration modes based on the use of software VibSoft ${ }^{\circledR}$ Polytec.

TABLE V. DAMPING COEFFICIENTS

\begin{tabular}{|c|c|}
\hline Vibration Modes of the Building & $\boldsymbol{\xi}(\mathbf{\%})$ \\
\hline $1^{\text {st }}$ & 1.98 \\
\hline $2^{\text {nd }}$ & 1.91 \\
\hline $4^{\text {th }}$ & 1.67 \\
\hline $5^{\text {th }}$ & 1.76 \\
\hline
\end{tabular}

\section{Results Analysis}

In this section of the paper, the numerical results calculated by the developed FEM model, see Figure 4, are compared with those obtained bade on the dynamic experimental monitoring, see Figures 6 to 14 .

\section{A. Natural frequencies}

In sequence, Table $\mathrm{V}$ presents the first five vibration modes and the respective natural frequencies values, obtained through the experimental tests and calculated based on the numerical modelling. 
Proc. of Eighth International Conference On Advances in Civil, Structural and Mechanical Engineering - ACSM 2018 Copyright (C) Institute of Research Engineers and Doctors, USA. All rights reserved.

ISBN: 978-1-63248-154-2 doi: 10.15224/978-1-63248-154-2-13

TABLE VI. NATURAL FREQUENCIES

\begin{tabular}{|c|c|c|c|c|}
\hline \multirow{2}{*}{$\begin{array}{c}\text { Mode } \\
\text { Shape }\end{array}$} & \multirow{2}{*}{$\begin{array}{c}\text { Vibration } \\
\text { Mode }\end{array}$} & \multirow{2}{*}{$\begin{array}{c}\text { FEM of } \\
\text { the } \\
\end{array}$} & Building & \multicolumn{2}{|c|}{ Experimental Monitoring } \\
\cline { 4 - 5 } $1^{\text {st }}$ & $\begin{array}{c}\text { Bending } \\
\text { around X }\end{array}$ & 2.67 & 2.54 & 2.50 \\
\hline $2^{\text {nd }}$ & $\begin{array}{c}\text { Bending } \\
\text { around Z }\end{array}$ & 2.76 & 2.73 & 2.69 \\
\hline $3^{\text {rd }}$ & $\begin{array}{c}\text { Torsion } \\
\text { around Y }\end{array}$ & 4.83 & - & - \\
\hline $4^{\text {th }}$ & $\begin{array}{c}\text { Bending } \\
\text { around Z }\end{array}$ & 8.46 & 8.06 & 7.81 \\
\hline $5^{\text {th }}$ & $\begin{array}{c}\text { Bending } \\
\text { around X }\end{array}$ & 9.04 & 9.13 & 8.94 \\
\hline
\end{tabular}

Based on the results presented in Table VI, is possible to verify, quantitatively, that the order of magnitude of the natural frequencies values numerically calculated is close to those experimentally obtained. Comparing the natural frequencies values calculated by the FEM model with those related to the PDV system, regarding the $1^{\text {st }}$ vibration mode (bending around the $\mathrm{Z}$ axis), there is a difference equal to $6.58 \%$, between the numerical and the experimental results obtained through PDV system. When the $2^{\text {nd }}$ mode shape (bending around the $\mathrm{X}$ axis) is considered in the analysis this difference between the frequencies values is only equal to $2.6 \%$. In this investigation, due to the position of the accelerometers uses in the experimental tests, the $3^{\text {rd }}$ mode (torsion with respect to the axis) was not experimentally evaluated. However, the $4^{\text {th }}$ and $5^{\text {th }}$ vibration modes presented differences related to the frequencies equal to $8.3 \%$ and $1.1 \%$, respectively.

\section{B. Vibration modes}

The experimental tests were performed considering the free vibration of the studied model, with the accelerometers positioned at the heights of $167.1 \mathrm{~cm} ; 144.1 \mathrm{~cm}$ and $61.6 \mathrm{~cm}$ of the structure. The position of the accelerometers was modified in each experimental test, in order to obtain the mode shapes of the building at the $\mathrm{X}$ and $\mathrm{Z}$ directions. Based on the natural frequencies of each mode, it was possible to filter the displacements signals of each accelerometer as a function of the frequency of the desired mode shape.

Based on the comparisons of the filtered signals of each accelerometer, related to the differences in the amplitudes values, it was possible to normalize these differences and then set up the vibration modes. This way, Figures 15 and 16 exhibits, the vibration modes performed through this experimental procedure, compared to the numerically obtained mode shapes. In Figures 15 and 16 it can be seen the concordance between the experimental and numerical results related to the mode shapes and consequently it is possible to conclude that the reliability of the developed numerical model (FEM model of the HDF building) is fully guaranteed.

\section{Forced vibration tests}

Following the same strategy, the HDF building numerical dynamic structural response was calculated and compared with the experimental results. To do this task, an impulsive load, see Figure 10, was applied at a selected point on the investigated building model, at the global $\mathrm{Z}$ direction $(\mathrm{h}=$ $149.6 \mathrm{~cm})$, based on the use of an impact hammer connected to an accelerometer.

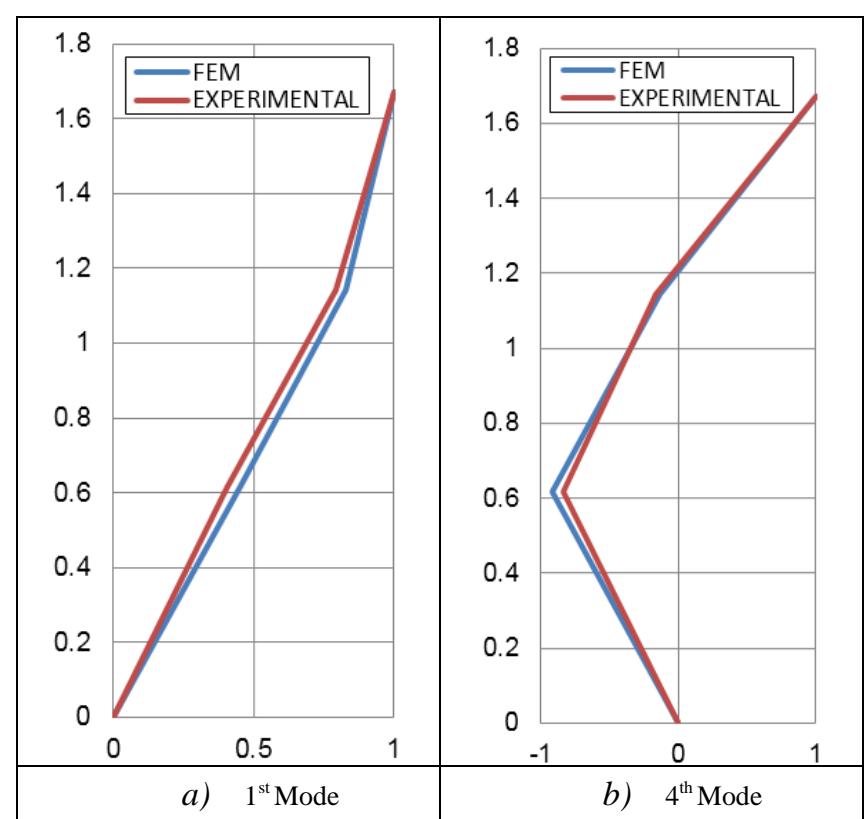

Figure 15. Comparison between the vibration modes obtained by numerical modelling and experimental monitoring: $\mathrm{X}$ direction.

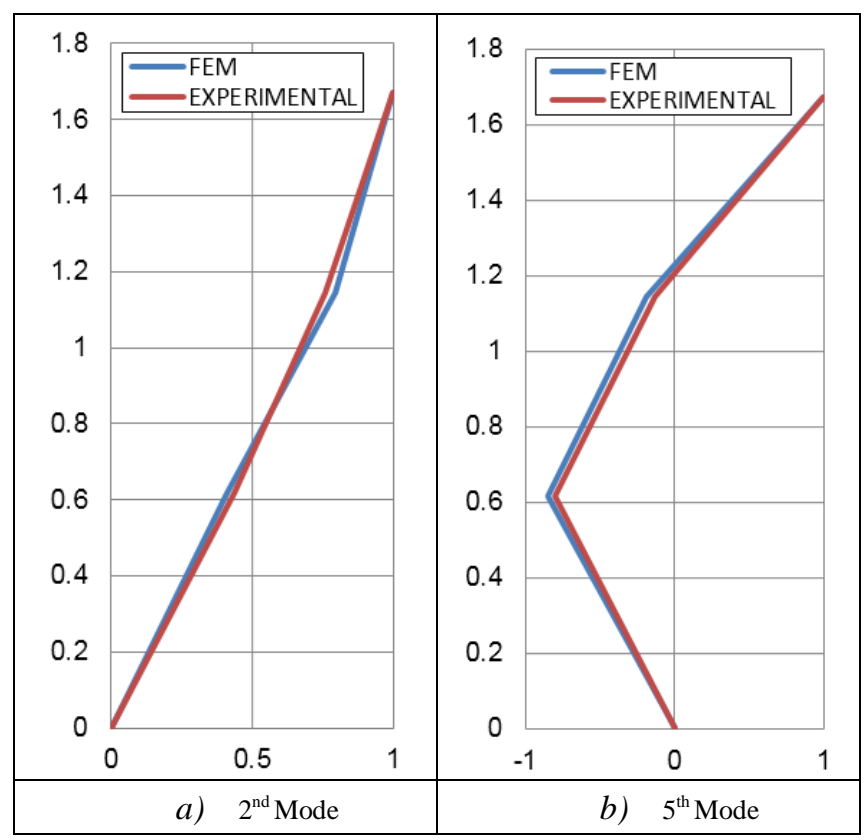

Figure 16. Comparison between the vibration modes obtained by numerical modelling and experimental monitoring: $\mathrm{Z}$ direction.

The same dynamic force was applied on the FEM model and a transient analysis was carried out. The horizontal translational displacement response, along the time, was derived aiming to obtain the velocity and in sequence to compare these values with those obtained based on the dynamic experimental monitoring of the building.

This way, Figures 17 and 18 present the experimental and numerical structural responses in time and frequency domains. It can be seen that the results calculated based on a transient dynamic analysis, using the developed FEM model, was close to experimental results obtained by the dynamic experimental monitoring. It must be emphasized that the maximum energy peak transfer has occurred at the same expected frequencies. 
Proc. of Eighth International Conference On Advances in Civil, Structural and Mechanical Engineering - ACSM 2018 Copyright (C) Institute of Research Engineers and Doctors, USA. All rights reserved.

ISBN: 978-1-63248-154-2 doi: 10.15224/978-1-63248-154-2-13

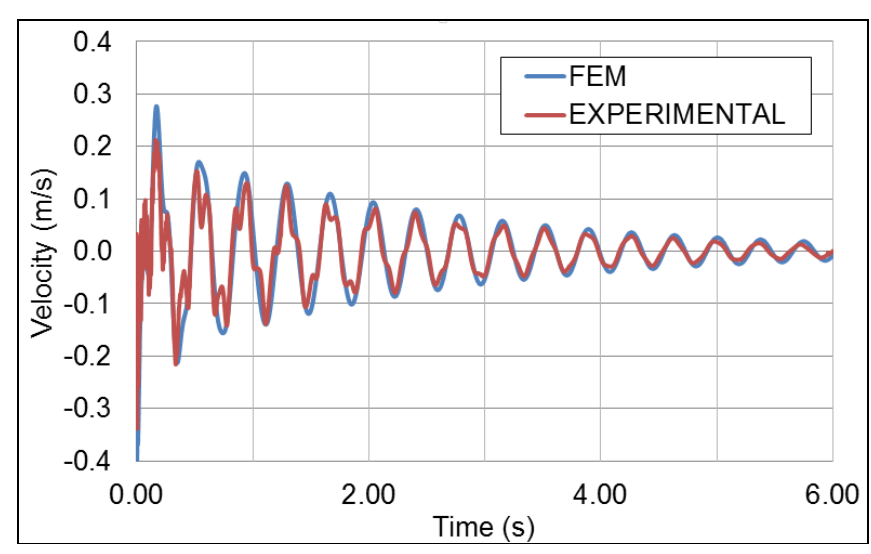

Figure 17. Dynamic structural response in time domain: FEM versus dynamic experimental monitoring.

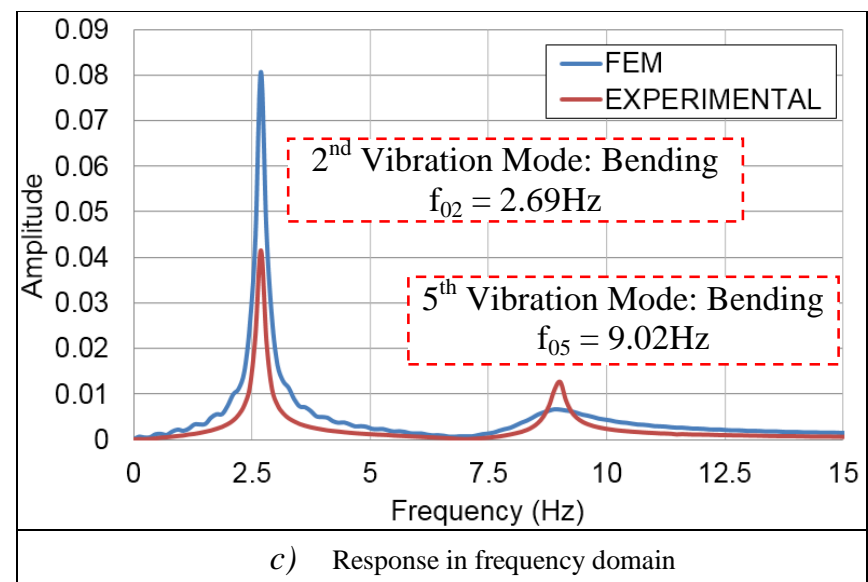

Figure 18. Dynamic structural response in frequency domain: FEM versus dynamic experimental monitoring.

\section{vII. Conclusions}

In this work, the dynamic structural behaviour of a real 19 story building, constructed in laboratory, based on the use of HDF (High Density Fibreboard) was investigated, based on experimental dynamic monitoring and FEM simulations. The main purpose of this work is to develop procedures, aiming to adjust and calibrate the numeric model, in order to represent the real structural behavior of the building.

The results obtained along this analysis, regarding the natural frequencies values comparisons between the numerical versus experimental results, presents small differences, less than $3 \%$ at the global $\mathrm{Z}$ direction and a difference less than $9 \%$ was found when the $X$ direction was investigated. The differences associated with the $\mathrm{X}$ direction are probably related to the fact that the support conditions of the constructed HDF building model was considered fixed in the FEM, but the experimental modal analysis indicated that in fact this support conditions are semi-rigid.

Based on the structural response of the accelerometers positioned at different heights of the model it was possible to obtain the vibration modes related to bending in $\mathrm{X}$ and $\mathrm{Z}$ direction. These mode shapes obtained experimentally coincided with the vibration modes obtained through the numerical modal analysis, with very small differences. This way, it can be concluded that the developed building FEM represents the dynamic structural response of the constructed HDF building model, with a very good degree of reliability.
Finally, based on the dynamic experimental monitoring it was possible to obtain the structural damping coefficients of the model, which are relevant for the analysis and also necessary for the adjustment and calibration of the building FEM. Thus, considering the use of the calibrated numerical model, the dynamic structural response (forced vibration analysis) was calculated and compared to the experimental tests, indicating the agreement of the numerical model results with the experimental ones, and also a proper representation of the HDF building behaviour.

\section{Acknowledgment}

The authors gratefully acknowledge the financial support for this investigation provided by the Brazilian Science Foundation's CAPES, CNPq and FAPERJ.

\section{References}

[1] Bastos, L.S. Study of the structural behaviour and human comfort analysis of reinforced concrete buildings. MSc Dissertation. Civil Engineering Postgraduate Programme (PGECIV). State University of Rio de Janeiro (UERJ). Rio de Janeiro/RJ, Brazil, 2015.

[2] Bastos, L.S. "Study of the nondeterministic dynamic structural behaviour of buildings subjected to wind actions considering the soilstructure interaction effct. $\mathrm{PhD}$ Thesis (In development). Civil Engineering Postgraduate Programme (PGECIV). State University of Rio de Janeiro (UERJ). Rio de Janeiro/RJ, Brazil, 2018.

[3] Barile, A.. Modelling of the nondeterministic dynamic behaviour of reinforced concrete buildings (In development). MSc Dissertation. Civil Engineering Postgraduate Programme (PGECIV). State University of Rio de Janeiro (UERJ). Rio de Janeiro/RJ, Brazil, 2018.

[4] D.J. Ewins. Modal Testing: Theory and Practice. Research Study Press LTD., 1984.

[5] ANSYS Swanson Analysis Systems Inc. Theory Reference Manual (R.12.1), 2010.

\section{About Author (s):}

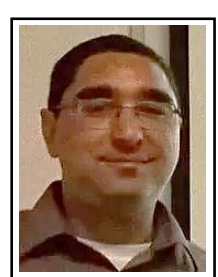

Leonardo de Souza Bastos is DSc student of the Civil Engineering Postgraduate Programme, PGECIV, of the Faculty of Engineering, FEN, of the State University of Rio de Janeiro, UERJ, Rio de Janeiro/RJ, Brazil.

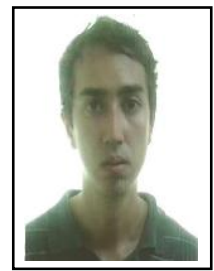

Alan Barile is MSc student of the Civil Engineering Postgraduate Programme, PGECIV, of the Faculty of Engineering, FEN, of the State University of Rio de Janeiro, UERJ, Rio de Janeiro/RJ, Brazil.

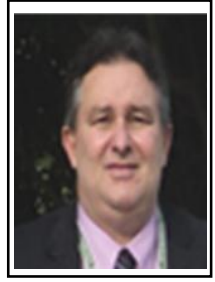

Prof. José Guilherme Santos da Silva, DSc, is Full Professor of the Civil Engineering Postgraduate Programme, PGECIV, of the Faculty of Engineering, FEN, of the State University of Rio de Janeiro, UERJ, Rio de Janeiro/RJ, Brazil.

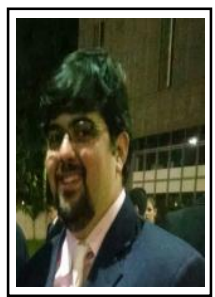

Gilvan Lunz Debona, DSc, is Adjunct Professor of the Department of Architecture and Urbanism Department, DAU, of Rural Federal University of Rio de Janeiro, UFRRJ, Rio de Janeiro/RJ, Brazil. 